\title{
Decreased expression of the CHD5 gene and its clinicopathological significance in breast cancer: Correlation with aberrant DNA methylation
}

\author{
ZHONGLIANG MA ${ }^{1 *}$, JINLIAN SONG ${ }^{2 *}$, SIMIN LIU $^{3}$, LINLIN HAN $^{4}$, \\ YANGPING CHEN $^{2}$, YAQIU WANG ${ }^{2}, \mathrm{CHUNDONG} \mathrm{YU}^{2}$ and $\mathrm{LIN} \mathrm{HOU}^{5}$
}

${ }^{1}$ Department of Breast Surgery, The Affiliated Hospital of Qingdao University, Qingdao, Shandong 266000;
${ }^{2}$ Department of Laboratory Medicine, The Affiliated Qingdao Women and Children's Hospital of Qingdao,
Qingdao, Shandong 266034; ${ }^{3}$ Department of PET Center, The Affiliated Hospital of Qingdao University,
Qingdao, Shandong 266000; ${ }^{4}$ Department of Pediatrics, Jinan Children's Hospital, Jinan, Shandong 250022;
${ }^{5}$ Department of Biochemistry, Medical College, Qingdao University, Qingdao, Shandong 266021, P.R. China

Received May 24, 2015; Accepted August 9, 2016

DOI: $10.3892 / 01.2016 .5147$

\begin{abstract}
Chromodomain helicase DNA binding protein 5 (CHD5) has been identified as a tumor suppressor in mouse models. Downregulation of CHD5 gene expression is frequently observed in breast cancer cells and tissues. This may be explained by deletions or other mutations; however, alternative mechanisms require investigation. Therefore, the present study evaluated whether CHD5 aberrant methylation has a role in primary breast tumors. A total of 389 patients with primary breast cancer (including 252 paraffin-embedded specimens and 137 fresh-frozen samples) were enrolled in the present study. In the current study, reverse transcription-polymerase chain reaction (RT-PCR) and nested-methylation-specific PCR were used to analyze the mRNA expression and promoter methylation of CHD5 genes in a large cohort of breast cancer patients, and to investigate their associations with the clinicopathological features of tumors. CHD5 expression was significantly suppressed in breast cancer tissues compared with normal breast tissues when analyzed by RT-PCR. Furthermore, DNA methylation of CHD5 was more prevalent in breast tumors than in normal tissues. CHD5 mRNA levels correlated with the degree of CHD5 methylation in breast cancer tissues. Clinicopathological correlation analysis revealed that CHD5 promoter methylation was associated with estrogen receptor and progesterone receptor status. Thus, downregulation of
\end{abstract}

Correspondence to: Professor Lin Hou, Department of Biochemistry, Medical College, Qingdao University, 38 Dengzhou Road, Qingdao, Shandong 266021, P.R. China

E-mail: linhou2005@126.com

*Contributed equally

Key words: breast cancer, chromodomain helicase DNA binding protein 5, gene expression, DNA methylation
CHD5, mediated by abnormal methylation, may contribute to the development and progression of breast cancer.

\section{Introduction}

Breast cancer is considered to be one of the most common malignances in women (1). Its occurrence and development is a multi-step process, which results from progressive accumulation of genetic and epigenetic alternations (2). Chromosomal loss, which leads to the inactivation of tumor suppressor genes, is one of the most common genetic alterations detected in human breast cancer (3). Previous publications have reported that human chromosome 1p36 is a region that is consistently deleted in human cancer (4-6), and chromodomain helicase DNA binding protein 5 (CHD5) is located on the short arm of this human chromosome (1p) (7). As a tumor suppressor, CHD5 is involved in proliferation, apoptosis and senescence via the $\mathrm{p} 19^{\mathrm{ARF}} / \mathrm{p} 53$ signaling pathway (8). CHD5 belongs to the chromodomain helicase DNA binding domain family, which includes nine members (CHD1-9) and is a subclass of the SWItch/sucrose non-fermentable proteins (9). Although CHD5 is involved in key cellular processes, the disrupted regulation of its expression has not been fully elucidated. To date, homozygous deletion or mutation cannot totally explain the loss of CHD5 expression, and additional mechanisms require investigation.

Impairment in chromatin remodeling activity, mediated by aberrant promoter methylation of candidate genes, including the CHD family, may be important in cancer pathology (10). During carcinogenesis, DNA methylation increases at promoters in selected $\mathrm{CpG}$ islands, but is lost at the majority of other genomic regions, resulting in silencing of tumor suppressor genes (11-13). These changes in DNA methylation are not due to any alteration in the DNA sequence (14). CHD5, as an ATP-dependent chromatin-remodeling enzyme, has been observed to exhibit aberrant methylation of $\mathrm{CpG}$ islands in human cancer cell lines and primary tumors, particularly gliomas and colon and breast carcinomas $(10,15)$. The present 
study focused on DNA methylation analysis of CHD5 protein, in order to elucidate an epigenetic mechanism of aberrant gene silencing. CHD5 expression was investigated using semi-quantitative reverse transcription-polymerase chain reaction (RT-PCR) in 137 fresh breast cancer specimens, as well as in corresponding normal tissues. In addition, CHD5 methylation was detected by nested-methylation specific PCR (MSP) in 389 sporadic breast cancer tissues. The association between CHD5 expression, CHD5 methylation status and several clinicopathological features of breast cancer tissues was also analyzed. The present study performed DNA methylation analysis of CHD5 protein, in order to elucidate an epigenetic mechanism of aberrant gene silencing in breast carcinoma.

\section{Materials and methods}

Tissue samples. All tissue samples were collected from surgical specimens of patients who underwent a mastectomy at the Affiliated Hospital of Qingdao University, (Qingdao, China) between January 2011 and January 2012. All patients provided informed consent and all procedures were approved by the hospital's ethics board. The patients were unrelated Chinese women, aged 26-86 years (mean, 52.3 \pm 10.6 years), with sporadic breast cancer. The present study analyzed a total of 389 tumor samples (252 paraffin-embedded tissues and 137 fresh-frozen tissues), which constituted $>50 \%$ of a tumor area. In addition, the present study analyzed fresh-frozen normal tissues from the same patients, located at least $5 \mathrm{~cm}$ away from the tumor sites. These tissues were collected following reconfirmation by a senior pathologist from the Affiliated Hospital of Qingdao University. The histological grade of each tumor was determined according to the modified Bloom-Richardson criteria (16), and Tumor-Node-Metastasis stages were determined using the official classification method (17).

Cell culture. Human breast cancer cell lines MDA-MB-231 (CHD5-negative) and MCF-7 (CHD5-positive) were obtained from Peking Union Medical College (Beijing, China). The cell lines were maintained in RPMI-1640 (Gibco; Thermo Fisher Scientific, Inc., Waltham, MA, USA) and supplemented with $10 \%$ fetal bovine serum (GE Healthcare Life Sciences, Logan, $\mathrm{UT}, \mathrm{USA}$ ) at $37^{\circ} \mathrm{C}$ in a humidified atmosphere with $5 \% \mathrm{CO}_{2}$.

RNA isolation and RT-PCR analysis. Total RNA was isolated using an RNAfast kit (Fastagen, Shanghai, China). RT-PCr was performed using the Access RT-PCR System (Promega Corporation, Madison, WI, USA). The PCR cycling conditions were as follows: 35 cycles of $95^{\circ} \mathrm{C}$ for $30 \mathrm{sec}, 60^{\circ} \mathrm{C}$ for $40 \mathrm{sec}$ and $72^{\circ} \mathrm{C}$ for $40 \mathrm{sec}$, followed by a final extension at $72^{\circ} \mathrm{C}$ for 5 min The primer sequences were as follows: CHD5 forward, 5'-TCAAGACAAACGTGTTCAAGTC-3' and reverse, 5'-ATT CAAGTGTTCTTCCACACAGC-3'; and GAPDH forward, 5'-CAAGGTCATCCATGACAACTTTG-3' and reverse, 5'-GTCCACCACCCTGTTGCTGTAG-3'. The PCR products were resolved by gel electrophoresis on $2 \%$ agarose gels, visualized under UV light and quantified using the JS-380 Gel Imaging Analysis System (Shanghai Peiqing Science and Technology, Co., Ltd., Shanghai, China). The CHD5 expression levels were normalized to GAPDH.
Bisulfite genomic sequencing analysis and nested-MSP. Genomic tumor DNA was isolated from the MDA-MB-231 and MCF-7 breast cancer cell lines or tissue samples using phenol-chloroform. Unmethylated cytosines in the DNA were to uracils using bisulfite in the EZ DNA Methylation-Gold ${ }^{\mathrm{TM}}$ kit (Zymo Research, Irvine, CA, USA). Previous studies have revealed that the region surrounding the transcription start sites $(+1)$ of genes may regulate their expression (18). The present study selected the region from -651 to -232 as the target fragment. The primers were designed by Methyl Primer Express version 1.0 software (Thermo Fisher Scientific, Inc.) using GenBank NM_015,557 (CHD5) as the reference sequence (outside primer: Sense, 5'-AGAAATTTTGAGGTAGAGATG GG-3', antisense, 5'-ACTTCAACACCAACTAAAAACCA-3', 418 bp; methylated primer: Sense, 5'-GGTTTCGGCGTT TGTGAATC-3', antisense, 5'-AACTTAACGAACCCGAAC GC-3', 180 bp; unmethylated primer: Sense, 5'-TGGGTTTTG GTGTTTGTGAATT-3'; antisense, 5'-CAAAACTTAACA AACCCAAACAC-3', 187 bp). First-round amplifications were performed in $25 \mu \mathrm{l}$ reactions using PerfectShot Ex Taq (Takara Bio, Inc., Otsu, Japan), including 10 pmol outside primer and 30 ng modified DNA, and the following cycle parameters: $95^{\circ} \mathrm{C}$ for $5 \mathrm{~min}, 35$ cycles at $95^{\circ} \mathrm{C}$ for $30 \mathrm{sec}, 52^{\circ} \mathrm{C}$ for $40 \mathrm{sec}$ and $72^{\circ} \mathrm{C}$ for $40 \mathrm{sec}$, followed by a final extension at $72^{\circ} \mathrm{C}$ for $5 \mathrm{~min}$. PCR products $(1 \mu \mathrm{l})$ were subjected to second-round amplifications using methylated and unmethylated primers, with the above cycle parameters. The PCR products were resolved by electrophoresis on $2.5 \%$ agarose gels, visualized under UV light and quantified using the JS-380 Gel Imaging Analysis System.

Statistical analysis. RT-PCR results are presented as the mean \pm standard deviation, and a Student's t-test was performed. Promoter methylation data were analyzed using the $\chi^{2}$ test in SPSS version 13.0 (SPSS, Inc., Chicago, IL, USA), and potential correlations with clinicopathological data were studied using unconditional logistic regression to estimate odds ratios (OR) and $95 \%$ confidence intervals (CI). The model was adjusted for age during diagnosis. $\mathrm{P}<0.05$ was considered to indicate a statistically significant difference.

\section{Results}

CHD5 mRNA levels in breast tumors and normal tissues. CHD5 mRNA was not detected or decreased in 92/137 fresh-frozen tumor samples and in 31/137 normal tissues (Fig. 1A). Therefore, downregulation of CHD5 expression was significantly increased in tumor tissue compared with corresponding normal tissue $\left(\chi^{2}=54.894 ; \mathrm{P}<0.001\right)$. In addition, CHD5 mRNA levels were significantly reduced in cancer specimens $(0.38 \pm 0.02)$ compared with normal tissue $(0.65 \pm 0.06 ; \mathrm{P}<0.001$; Fig. 1B).

Correlation between CHD5 promoter methylation and CHD5 expression. A correlation analysis revealed that loss of CHD5 expression was correlated with CHD5 methylation. Fig. 1C shows that the difference in CHD5 expression levels between tissues in which CHD5 was methylated and tissues in which CHD5 was unmethylated was statistically significant for cancerous and normal tissue samples. However, a small number of normal tissue samples exhibited CHD5 expression and promoter methylation (Table I). 
Table I. Association between CHD5 methylation and expression.

\begin{tabular}{|c|c|c|c|c|}
\hline \multirow[b]{2}{*}{ CHD5 methylation status } & \multicolumn{2}{|c|}{ CHD5 expression } & \multirow[b]{2}{*}{$\chi^{2}$} & \multirow[b]{2}{*}{ P-value } \\
\hline & + & - & & \\
\hline Tumor sample & & & 4.513 & 0.034 \\
\hline+ & 9 & 35 & & \\
\hline- & 36 & 57 & & \\
\hline Normal sample & & & 6.673 & 0.010 \\
\hline+ & 3 & 17 & & \\
\hline- & 103 & 14 & & \\
\hline
\end{tabular}

CHD5, chromodomain helicase DNA binding protein 5.
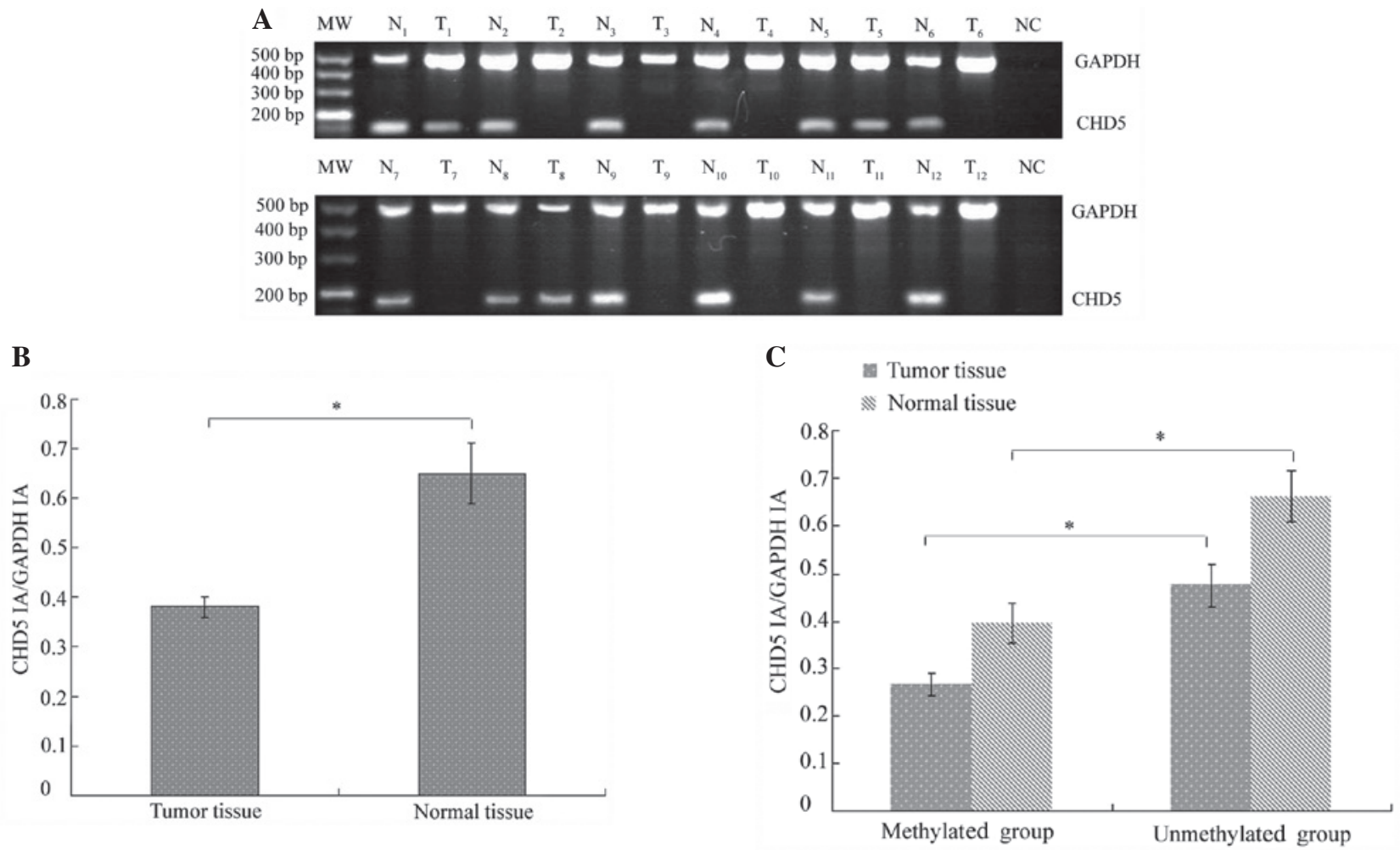

Figure 1. (A) CHD5 expression analysis was performed using reverse transcription-semi-quantitative PCR in breast tumor tissues and corresponding normal tissues. NC represents the PCR reaction without DNA. The GAPDH gene was used as an internal control. (B and C) The PCR products were scanned and analyzed using the Peiqing JS-380 Gel Imaging Analysis System following agarose gel electrophoresis. The IA score for each band was derived from the formula IA $=$ average absorbance $\mathrm{x}$ area $\left(\mathrm{mm}^{2}\right)$, and the CHD5 relative expression of each sample was represented in the following way: CHD5 IA/GAPDH IA. "P<0.05. CHD5, chromodomain helicase DNA binding protein 5; MW, molecular weight; T, breast tumor tissue; N, corresponding normal tissue; PCR, polymerase chain reaction; GAPDH, glyceraldehyde-3-phosphate dehydrogenase; IA, integral absorbance; NC, negative control.

Silencing of CHD5 is associated with promoter hypermethylation. Sodium bisulfite sequencing was performed on a 418 bp fragment with $39 \mathrm{CpG}$ dinucleotides located within the -651 to -232 island (Fig. 2A). The CHD5-negative cell line, MDA-MB-231, demonstrated hypermethylation of the CpG dinucleotides (Fig. 2B). By contrast, the CHD5-positive cell line MCF-7, exhibited lower levels of $\mathrm{CpG}$ dinucleotide methylation.

Nested-MSP analysis in primary breast tissues. The present study used nested-MSP analysis to study the methylation status of $\mathrm{CpG}$ islands. CHD5 promoter methylation was detected in 105/389 (27.1\%) primary breast tumor samples (data not shown), 61/252 paraffin-embedded tissue samples (data not shown), 44/137 fresh-frozen tumor samples and 20/137 normal tissue samples (Table I). Therefore, CHD5 promoter methylation was observed more frequently in breast cancer tissue samples compared with corresponding normal tissue samples $\left(\chi^{2}=8.590 ; \mathrm{P}=0.003\right)$, as confirmed by nested methylation-specific PCR (Fig. 3).

Correlation between promoter methylation and clinicopathological characteristics. The associations between individual gene methylation status and clinicopathological 
A

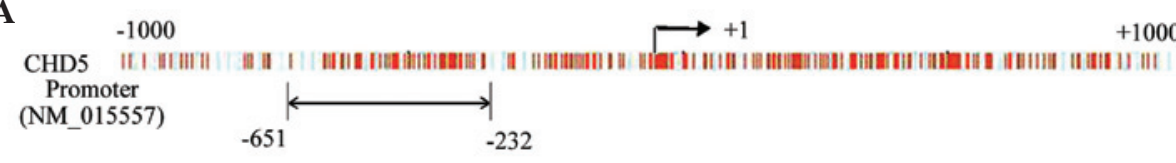

B

$\begin{array}{llllllllllllllllll}0 & 13 \% & 25 \% & 38 \% & 50 \% & 63 \% & 75 \% & 88 \% & 100 \%\end{array}$

MDA-MB-231

MCF-7

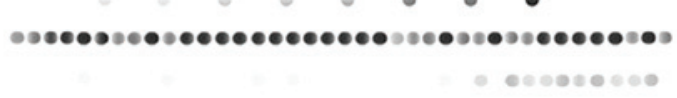

Figure 2. Methylation status of the CHD5 gene in the fragment from -651 to -232. (A) The CpG island of CHD5 surrounding the transcription start site. A fragment of $418 \mathrm{bp} \mathrm{(-651} \mathrm{to} \mathrm{-232),} \mathrm{encompassing} 39 \mathrm{CpG}$ dinucleotides with the $\mathrm{CpG}$ island, was selected for methylation analysis. (B) The bisulfite genomic sequencing of 8 individual clones was analyzed in MDA-MB-231 and MCF-7 breast cancer cell lines. The 39 dinucleotides are numbered in agreement with the sequence. The open circles represent the unmethylated dinucleotides, while the gray or blank circles represent various percentages of methylation. CHD5, chromodomain helicase DNA binding protein 5.

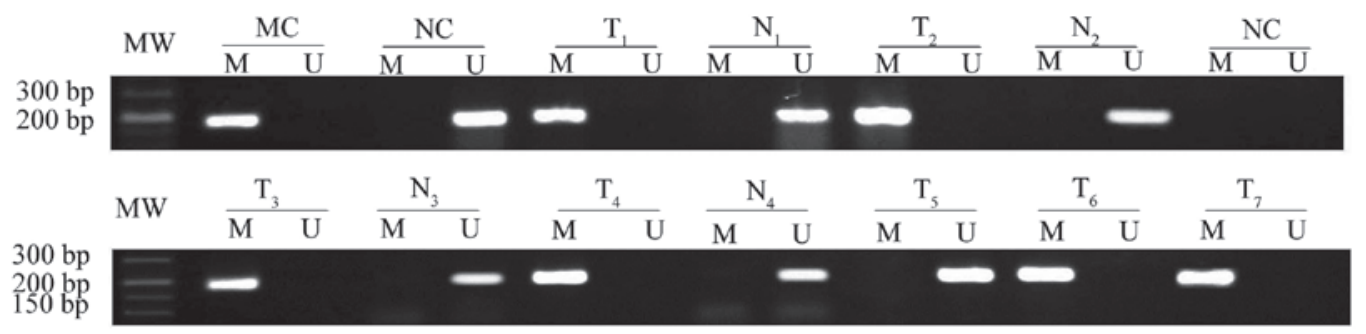

Figure 3. Nested methylation-specific PCR was used to analyze CHD5 methylation in breast cancer tissues and corresponding normal breast tissues. Genomic DNA from breast tissues treated with sodium bisulfite was amplified using methylated and unmethylated primers. MC and UC human genomic DNA were used as the positive control for methylated and unmethylated reactions, respectively. A blank control (NC) containing all PCR components without template DNA was also included in all PCR reactions. PCR, polymerase chain reaction; CHD5, chromodomain helicase DNA binding protein 5; T, breast cancer tissue; $\mathrm{N}$, corresponding normal breast tissues; $\mathrm{M}$, methylated; $\mathrm{U}$, unmethylated; $\mathrm{MC}$, universal methylated; UC, universal unmethylated; MW, molecular weight.

features of breast cancer are evaluated in Table II. Table II shows that the highest levels of CHD5 methylation were observed in breast tumor samples with either (or both) estrogen receptor (ER)/progesterone receptor (PR) negative status [OR, 0.47 ; 95\% CI, 0.24-0.92; P=0.023; OR, 0.50; 95\% CI, 0.29-0.87; $\mathrm{P}=0.028$ ).

\section{Discussion}

Evidence that CHD5 functions as a tumor suppressor in human cancer has been observed in studies of neuroblastoma, in which CHD5 mRNA expression was downregulated potentially via promoter methylation in tumors (19). Furthermore, it also has been reported that aberrant CHD5 promoter methylation was detected in gastric, colorectal, ovarian and lung cancer (20-23). However, to the best of our knowledge, the role of CHD5 promoter methylation status in breast cancer has not been evaluated. In the present study, the expression of CHD5 was detected at a transcriptional level. The results revealed that CHD5 mRNA was downregulated in 92/137 breast tumors and 31/137 normal tissues. Therefore, downregulation of CHD5 expression was significantly more frequent in tumors compared with corresponding normal tissues $(\mathrm{P}<0.001)$. To the best of our knowledge, aberrant CHD5 promoter methylation could additionally explain low expression levels or silencing that are not caused by chromatin deletion or other mutations. Mulero-Navarro and Esteller (10) reported that CHD5 was silenced by aberrant promoter $\mathrm{CpG}$ island methylation in human cancer. However, this study mainly focused on cancer cell lines and limited cases of primary tumors (10). Based on the above research, the present study selected 389 cases of breast primary tumors (including 252 paraffin embedded specimens and 137 fresh-frozen cases), determined the methylation status and investigated the correlation between CHD5 methylation and expression levels and clinicopathological characteristics.

There is increasing evidence that promoter methylation of tumor suppressor genes has a significant role in the pathogenesis of tumors, including breast tumors $(10,24)$. In the present study, MSP revealed aberrant CHD5 promoter methylation in 105/389 breast tumor samples, 44/137 fresh-frozen tumor samples and 20 normal tissue samples. CHD5 methylation was more frequent in breast tumors compared with normal tissues $(\mathrm{P}=0.003)$. Furthermore, the difference in CHD5 expression levels between tissues in which CHD5 was methylated and tissues in which CHD5 was unmethylated was statistically significant for the tumor samples $(\mathrm{P}=0.034)$ and for the corresponding normal tissues $(\mathrm{P}=0.010)$. However, a small number of normal samples exhibited CHD5 expression and aberrant promoter methylation. A potential explanation for this result is that samples may have already undergone premalignant mutations affecting CHD5, as this process has been previously observed in tumor suppressor genes in certain breast tumors $(25,26)$. The results of the present study suggest that aberrant DNA methylation may affect CHD5 expression. Furthermore, it is possible that the observed aberrant methylation of the CHD5 promoter in breast tumors is critical for tumorigenesis.

To additionally characterize the aberrant CHD5 promoter methylation in tumor samples, the present study 
Table II. Clinicopathological features of the 389 patients with primary breast tumors according to the methylation status of CHD5.

\begin{tabular}{|c|c|c|c|c|}
\hline \multirow[b]{2}{*}{ Clinical data } & \multirow[b]{2}{*}{ Samples, $\mathrm{n}$} & \multicolumn{2}{|c|}{ CHD5 } & \multirow[b]{2}{*}{ P-value } \\
\hline & & M & OR $(95 \% \mathrm{CI})$ & \\
\hline \multicolumn{5}{|c|}{ Menopausal status } \\
\hline Pre- & 227 & 54 & 1.00 & \\
\hline Post- & 162 & 33 & $0.58(0.24-1.43)$ & 0.4251 \\
\hline \multicolumn{5}{|l|}{ Tumor size $(\mathrm{cm})$} \\
\hline$<1.0$ & 7 & 1 & 1.00 & \\
\hline $1.0-1.9$ & 136 & 27 & $1.65(0.15-17.98)$ & 0.7170 \\
\hline $2-3$ & 200 & 46 & $2.34(0.22-25.42)$ & 0.5890 \\
\hline$\geq 3.1$ & 46 & 13 & $3.20(0.27-37.46)$ & 0.4350 \\
\hline \multicolumn{5}{|l|}{ Differentiation } \\
\hline Well & 32 & 6 & 1.00 & \\
\hline Moderate & 207 & 50 & $1.33(0.45-3.90)$ & \\
\hline Poor & 150 & 31 & $1.25(0.42-3.79)$ & 0.6467 \\
\hline \multicolumn{5}{|c|}{ Lymph node status } \\
\hline Negative & 238 & 55 & 1.00 & \\
\hline Positive & 151 & 32 & $0.87(0.50-1.53)$ & 0.6583 \\
\hline \multicolumn{5}{|c|}{ Metastatic disease at presentation } \\
\hline Negative & 303 & 67 & 1.00 & \\
\hline Positive & 86 & 20 & $1.07(0.56-2.04)$ & 0.8223 \\
\hline \multicolumn{5}{|l|}{ TNM stage } \\
\hline $0 / \mathrm{I}$ & 87 & 15 & 1.00 & \\
\hline II & 216 & 52 & $1.51(0.77-2.95)$ & 0.1950 \\
\hline III/IV & 86 & 20 & $1.35(0.63-2.91)$ & 0.3250 \\
\hline \multicolumn{5}{|l|}{ ER status } \\
\hline Negative & 242 & 45 & 1.00 & \\
\hline Positive & 147 & 42 & $0.47(0.27-0.82)$ & 0.0230 \\
\hline \multicolumn{5}{|l|}{ PR status } \\
\hline Negative & 205 & 43 & 1.00 & \\
\hline Positive & 184 & 44 & $0.67(0.38-1.19)$ & 0.4876 \\
\hline \multicolumn{5}{|l|}{ ER/PR status } \\
\hline Both negative & 187 & 33 & 1.00 & \\
\hline Either positive & 73 & 22 & $1.50(0.24-0.92)$ & 0.0280 \\
\hline Both positive & 129 & 32 & $0.65(0.38-1.12)$ & 0.1220 \\
\hline \multicolumn{5}{|l|}{ p53 status } \\
\hline Wild-type & 160 & 36 & 1.00 & \\
\hline Mutant & 229 & 51 & $1.09(0.62-1.91)$ & 0.6337 \\
\hline \multicolumn{5}{|l|}{ C-erbB-2 status } \\
\hline Negative & 270 & 58 & 1.00 & \\
\hline Positive & 119 & 29 & $1.60(0.89-2.90)$ & 0.5287 \\
\hline \multicolumn{5}{|c|}{ Ki67 proliferation index, $\%$} \\
\hline$<10$ & 28 & 9 & 1.00 & \\
\hline $10-32$ & 217 & 44 & $0.85(0.31-2.33)$ & 0.1510 \\
\hline$\geq 33$ & 144 & 34 & $0.85(0.30-2.41)$ & 0.3400 \\
\hline
\end{tabular}

CHD5, chromodomain helicase DNA binding protein 5; OR, odds ratio; CI, confidence interval; TNM, tumor-node-metastasis; ER, estrogen receptor; PR, progesterone receptor; $\mathrm{M}$, methylated.

evaluated potential associations between CHD5 methylation status and various clinicopathological parameters. CHD5 was more frequently methylated in breast tumor samples with ER/PR (or both) negative status than in samples with ER/PR (or both) positive status. The ER/PR status has been recognized as a prognostic factor in patients with breast carcinoma, and has been noted to be a predictive marker for the response to treatment with endocrine therapy (27). The presence of ER and PR is predictive of the response to treatment with the anti-estrogen drug tamoxifen (28). Previous studies have provided evidence 
that ER and PR expression patterns are influenced by changes in the chromatin structure during transcription $(29,30)$. The present study demonstrated that CHD5 exhibited aberrant $\mathrm{CpG}$ island methylation in primary tumors of breast carcinoma. CHD5 is located at human chromosome $1 \mathrm{p} 36$, which is recurrently deleted in human breast cancer (4-6). Furthermore, the results provided evidence that there is a correlation between aberrant CHD5 promoter methylation and ER and PR status. Although a previous study reported that CHD5 protein expression significantly correlated with ER/PR status in breast tumors (31), further research is required, as this has been reported infrequently. Therefore, it is possible that ER/PR status may be involved in the association between CHD5 methylation and breast cancer risk. Further studies are required to investigate whether the CHD5 methylation status may have a role in predicting the response of breast cancer with ER/PR negative status to therapy.

In conclusion, the present study indicated that promoter methylation and downregulation of CHD5 at the RNA level were common in breast cancer, and CHD5 downregulation occurred in part as a result of promoter methylation. In addition, the results of the present study provide evidence that CHD5 methylation is correlated with ER/PR status. Such knowledge may assist in understanding the mechanism underlying the pathophysiology of breast cancer with ER/PR negative status.

\section{References}

1. DeSantis C, Siegel R, Bandi P and Jemal A: Breast cancer statistics. CA Cancer J Clin 61: 409-418, 2011.

2. Fucito A, Lucchetti C, Giordano A and Romano G: Genetic and epigenetic alterations in breast cancer: What are the perspectives for clinical practice? Int J Biochem Cell Biol 40: 565-575, 2008.

3. van Wezel T, Lombaerts M, van Roon EH, Philippo K, Baelde HJ, Szuhai K, Cornelisse CJ and Cleton-Jansen AM: Expression analysis of candidate breast tumour suppressor genes on chromosome 16q. Breast Cancer Res 7: R998-R1004, 2005.

4. Bagchi A and Mills AA: The quest for the 1p36 tumor suppressor. Cancer Res 68: 2551-2556, 2008.

5. Bièche I, Champème MH, Matifas F, Cropp CS, Callahan R and Lidereau R: Two distinct regions involved in $1 \mathrm{p}$ deletion in human primary breast cancer. Cancer Res 53: 1990-1994, 1993.

6. Praml C, Finke LH, Herfarth C, Schlag P, Schwab M and Amler L: Deletion mapping defines different regions in 1p34.2-pter that may harbor genetic information related to human colorectal cancer. Oncogene 11: 1357-1362, 1995.

7. Costello JF, Frühwald MC, Smiraglia DJ, Rush LJ, Robertson GP, Gao X, Wright FA, Feramisco JD, Peltomäki P, Lang JC, et al: Aberrant $\mathrm{CpG}$-island methylation has non-random and tumor-type-specific patterns. Nat Genet 24: 132-138, 2000.

8. Bagchi A, Papazoglu C, Wu Y, Capurso D, Brodt M, Francis D, Bredel M, Vogel $\mathrm{H}$ and Mills AA: CHD5 is a tumor suppressor at human 1p36. Cell 128: 459-475, 2007.

9. Kolla V, Zhuang T, Higashi M, Naraparaju K and Brodeur GM: Role of CHD5 in human cancers: 10 years later. Cancer Res 74: 652-658, 2014

10. Mulero-Navarro S and Esteller M: Chromatin remodeling factor CHD5 is silenced by promoter $\mathrm{CpG}$ island hypermethylation in human cancer. Epigenetics 3: 210-215, 2008.

11. Clark SJ and Melki J: DNA methylation and gene silencing in cancer: Which is the guilty party? Oncogene 21: 5380-5387, 2002.
12. Das PM and Singal R: DNA methylation and cancer. J Clin Oncol 22: 4632-4642, 2004.

13. Jones PA and Baylin SB: The epigenomics of cancer. Cell 128: 683-692, 2007.

14. Holliday R: The inheritance of epigenetic defects. Science 238: 163-170, 1987.

15. Mokarram P, Kumar K, Brim H, Naghibalhossaini F, Saberi-firoozi M, Nouraie M, Green R, Lee E, Smoot DT and Ashktorab H: Distinct high-profile methylated genes in colorectal cancer. PLoS One 4: e7012, 2009.

16. Elston CW and Ellis IO: Pathological prognostic factors in breast cancer. I. The value of histological grade in breast cancer: Experience from a large study with long-term follow-up. Histopathology 19: 403-410, 1991.

17. Veronesi U, Viale G, Rotmensz N and Goldhirsch A: Rethinking TNM: Breast cancer TNM classification for treatment decision-making and research. Breast 15: 3-8, 2006.

18. Zou B, Chim CS, Zeng H, Leung SY, Yang Y, Tu SP, Lin MC, Wang J, He H, Jiang SH, et al: Correlation between the single-site $\mathrm{CpG}$ methylation and expression silencing of the XAF1 gene in human gastric and colon cancers. Gastroenterology 131: 1835-1843, 2006

19. Fujita T, Igarashi J, Okawa ER, Gotoh T, Manne J, Kolla V, Kim J, Zhao H, Pawel BR, London WB, et al: CHD5, a tumor suppressor gene deleted from $1 \mathrm{p} 36.31$ in neuroblastomas. J Natl Cancer Inst 100: 940-949, 2008.

20. Wang X, Lau KK, So LK and Lam YW: CHD5 is down-regulated through promoter hypermethylation in gastric cancer. J Biomed Sci 16: 95, 2009.

21. Fatemi M, Paul TA, Brodeur GM, Shokrani B, Brim H and Ashktorab $\mathrm{H}$ : Epigenetic silencing of CHD5, a novel tumor-suppressor gene, occurs in early colorectal cancer stages. Cancer 120: 172-180, 2014

22. Gorringe KL, Choong DY, Williams LH, Ramakrishna M, Sridhar A, Qiu W, Bearfoot JL and Campbell IG: Mutation and methylation analysis of the chromodomain-helicase-DNA binding 5 gene in ovarian cancer. Neoplasia 10: 1253-1258, 2008.

23. Zhao R, Yan Q, Lv J, Huang H, Zheng W, Zhang B and Ma W: CHD5, a tumor suppressor that is epigenetically silenced in lung cancer. Lung Cancer 76: 324-331, 2012.

24. Koyama H, Zhuang T, Light JE, Kolla V, Higashi M, McGrady PW, London WB and Brodeur GM: Mechanisms of CHD5 Inactivation in neuroblastomas. Clin Cancer Res 18: 1588-1597, 2012

25. Rinner B, Gallè B, Trajanoski S, Fischer C, Hatz M, Maierhofer T, Michelitsch G, Moinfar F, Stelzer I, Pfragner R and Guelly C: Molecular evidence for the bi-clonal origin of neuroendocrine tumor derived metastases. BMC Genomics 13: 594, 2012.

26. Futscher BW: Epigenetic changes during cell transformation. Adv Exp Med Biol 754: 179-194, 2013.

27. Ferguson NL, Bell J, Heidel R, Lee S, Vanmeter S, Duncan L, Munsey B, Panella T and Orucevic A: Prognostic value of breast cancer subtypes, Ki-67 proliferation index, age, and pathologic tumor characteristics on breast cancer survival in Caucasian women. Breast J 19: 22-30, 2013.

28. Bardou VJ, Arpino G, Elledge RM, Osborne CK and Clark GM: Progesterone receptor status significantly improves outcome prediction over estrogen receptor status alone for adjuvant endocrine therapy in two large breast cancer databases. J Clin Oncol 21: 1973-1979, 2003.

29. Yan L, Yang X and Davidson NE: Role of DNA methylation and histone acetylation in steroid receptor expression in breast cancer. J Mammary Gland Biol Neoplasia 6: 183-192, 2001.

30. Yang X, Ferguson AT, Nass SJ, Phillips DL, Butash KA, Wang SM, Herman JG and Davidson NE: Transcriptional activation of estrogen receptor alpha in human breast cancer cells by histone deacetylase inhibition. Cancer Res 60: 6890-6894, 2000.

31. Wu X, Zhu Z, Li W, Fu X, Su D, Fu L, Zhang Z, Luo A, Sun X, Fu L and Dong JT: Chromodomain helicase DNA binding protein 5 plays a tumor suppressor role in human breast cancer. Breast Cancer Res 14: R73, 2012. 